\title{
FAMILIAL MEDITERRANEAN FEVER
}

\author{
Adem Kucuk', Ilknur Albayrak Gezer², Ramazan Ucar³, Ali Yavuz Karahan ${ }^{4}$
}

Necmettin Erbakan Üniversitesi Romatoloji Bilim Dalı Konya,Turkey¹, Eğitim ve Araştırma Hastanesi Fiziksel Tıp ve Rehabilitasyon Bölümü Konya, Turkey², Konya Eğitim ve Araştırma Hastanesi, Dahiliye Kliniği, Konya, Turkey³, Devlet Hastanesi Fiziksel Tıp ve Rehabilitasyon Bölümü Konya, Turkey ${ }^{4}$

Summary: Familial Mediterranean Fever is an autosomal recessive inherited disease with a course of autoinflammation, which is characterized by the episodes of fever and serositis. It affects the populations from Mediterranean basin. Genetic mutation of the disease is on MEFV gene located on short arm of Chromosome 16. The disease is diagnosed based on clinical evaluation. Amyloidosis is the most important complication. The only agent that decreases the development of amyloidosis and the frequency and severity of the episodes is colchicine, which has been used for about 40 years. In this review, we aimed to discuss especially the most recent advances about Familial Mediterranean Fever which is commonly seen in our population.

Key words: Familial Mediterranean Fever; MEFV; Amyloidosis

\section{Description}

Familial Mediterranean Fever (FMF) is an autosomal recessive inherited autoinflammatory disease characterized by self-limiting fever and inflammation that may be localized in peritoneum, pleura, joint or skin (1).

\section{FMF History}

The disease has been firstly defined as "unusual recurrent peritonitis" by Janeway and Mosenthal in a 16-years-old Jewish girl with recurrent fever, abdominal pain and leukocytosis in 1908 (2). It has been described as "benign recurrent peritonitis" by Siegal in 1945 (3), due to the observation of the same clinical findings in 10 patients. One year after, the first case was published in our country (4). The association of the disease with amyloidosis and familial inheritance has been demonstrated by Mamau and Kattan (5) at the beginning of 1950s. Heller et al. (6) has named the disease as "Familial Mediterranean Fever" in 1958, based on its autosomal recessive inheritance trait, its high prevalence in people of Mediterranean origin and its course with recurrent febrile episodes. An important step was made in its treatment in 1972. In the publications of Ozkan et al. (7) and Goldfinger (8), it was reported that colchicine therapy was efficient for preventing amyloidosis in addition to prevention of attacks. Another important advance was that, in 1997, the gene responsible for FMF was cloned on short arm of the Chromosome 16 concomitantly and independently by international FMF Consortium and French FMF Consortium (9-10).

\section{Epidemiology}

FMF is a commonly seen disease in Jewish, Armenian, Turkish and Arabic communities. In Sephardic Jewish people and in three other ethnic group, its prevalence ranges between $1: 200$ and $1: 1000$ (11). Although it is a Mediterranean-originated disease, the migrations caused other communities to be affected. Based on most recent reports, it is also seen in European countries such as Italy and Greece. It may also be rarely seen in other ethnic groups such as Japanese people (12). In the prevalence studies performed in our country, interregional differences were found. While the prevalence of FMF was reported to be $0.25 \%$ in Sivas area by Onen et al. (13), it was reported to be lower (0.027\%) in Denizli area by Cobankara et al. (14). In the study performed by Kisacik et al. (15), the incidence was reported to be $0.82 \%$ in the people aged above 18 -years-old in Tokat and surrounding area in the North of Turkey. In the basin study performed by Cakir et al., the incidence was $0.006 \%$ (16). In a survey performed in Zara district of the province of Sivas, the prevalence of FMF was $0.88 \%$ (17). Data that strikingly demonstrated this interregional difference were the data of FMF study group (18). Although $94 \%$ of the subjects were living in the Western region of the country, familial origins were east of the Central Anatolia and Black Sea region in $70 \%$ of the subjects.

The results of the study performed by Turkish FMF group (18) showed that the incidence of the disease was nearly equal in both genders (M/F: 1.2/1). In 30-50\% of the patients, the familial history was positive. FMF occurs in the same generation rather than consecutive generations (19). 


\section{Genetics}

FMF is an autosomal recessive disease. In 1997, the gene responsible for FMF was cloned in Chromosome 16 independently by French FMF Consortium and international FMF Consortium. MEFV gene (MEditerranean FeVer) responsible for FMF was called as Pyrin by international FMF Consortium and as Marenostrin by French Consortium (9-10). MEFV is gene consisted of 10 exons and 3505 nucleotides, which is located in $16 \mathrm{p} 13.3$. This gene that causes FMF encodes 781-amino acid pyrin/marenostrin protein (19).

In the communities in which FMF is most common, $85 \%$ of the genetic mutations were encoded in exon 10 and exon 2. While exon 10 contains 4 principal mutations (M694V, V726A, M680I, M694I), exon 2 contains 1 mutations (E148Q). Pyrin/marenostrin encoded in MEFV gene plays a role in the regulation of the inflammation showing an autoregulator effect on leukocytes (20). In the study performed by Yilmaz et al., it was reported that in our country, 5 mutations including M694V, E148Q, M680I, V726I, M694I were common (21). In the evaluation performed by FMF study group, M694V (51.4\%), M680I (14.4\%), V726I $(8.6 \%)$ were reported to be the most common mutations (18). Dundar et al. (22) found in a cohort including 2967 patients (866 men, 1201 women) during 3-year follow-up that the most common mutations were M694V, E148Q, M680I and V726I. No mutation was found in 1023 patients (49.5\%) and this observation was attributed to unknown mutation, genetic heterogeneity, rare mutation or the lack of strip for some mutations.

\section{Pathogenesis}

\section{(a) Physiological Inflammatory Response}

The factors that cause fever may be classified in two groups. First group include exogenous bacterial cell wall components (such as liposaccharides) and other microbial products. These agents lead to protein response called PAMP (pathogen-associated molecular pattern). These PAMPs are recognized by Toll-like receptors present in the innate immune system. Furthermore, there are also other particular proteins that perceive pathogenic components and thereby lead to inflammatory response. These include NOD-LRR (nucleotide-binding oligomerization domain leucine rich repeat proteins) proteins (23-27).

Second group include IL-1 $\beta$, IL- $1 \alpha$, TNF $\alpha$, TNF $\beta$ and IL-6 known as endogenous pyrogens $(24,26)$. IL- $1 \beta$ is initially synthesized as an inactive precursor with a molecular weight of $31 \mathrm{kDa}$ (pro-IL-1 $\beta$ ). Pro-IL-1 $\beta$ is synthesized as a result of Toll-like receptor activation due to the effect of microbial products. Activation of pro-IL- $1 \beta$ requires its division in a protein of $17 \mathrm{kDa}$. This division is performed by caspase-1. Caspase- 1 is known as IL-1 $\beta$ converting enzyme. Furthermore, caspase-1 itself is synthesized as an inactive precursor protein (pro-caspase-1). Thereafter, it is activated as a result of NOD-LRR protein stimulation and activation of the inflamasome (27). The persistent inflammation is associated with increased serum amyloid A protein (SAA) that leads to secondary amyloidosis deposition mostly in the kidney, gut, spleen, liver and bone marrow (28).

\section{(b) Pyrin and FMF}

The majority of FMF-associated mutations are located in the B30.2 (SPRY) domain, which functions as a ligand binding or a signal transduction domain, at the carboxy terminus of the protein (29). Pyrin expression is enhanced by inflammatory mediators such as IFN $\alpha$, TNF $\alpha$ and IL-4. Pyrin contains 4 domains, including NH2-terminal pyrin domain that contains 92 amino acids (PYD), B-box, CC (coiled-coil) and, lastly, B30.2/rfp/SPIa and ryanodine receptor (SPRY)/ domain (also known as PRYSPRY domain). Pyrin interacts with pyrin domain in common adaptor apoptosis-associated speck-like protein (ASC), affecting the activation of IL-1 $\beta$ (27, 30-32).

Many hypotheses were suggested for the pathogenesis of FMF. Among these, most important two are as follows:

1. Sequestration hypothesis: Pyrin inhibits IL-1 $\beta$ activation related to caspase-1. It achieves this inhibition by competitive binding to ASC and caspase-1 (33-34). Chae et al. (34) reported that the binding of pyrin to ASC led to an impairment of the inflammasome structure. Therefore, inflammatory process is interrupted. Furthermore, it directly binds to pro-caspase-1 and caspase-1, independently from ASC, via B30.2/rpf/SPYD domain. Thereby, IL-1 $\beta$ activation is prevented (33-34).

2. Pyrin-Inflammasome hypothesis: Yu et al (35) demonstrated the proinflammatory effects of the pyrin on IL-1 $\beta$. Thereby, pyrin may be playing a role in the formation of an inflammasome complex that leads to caspase-1 activation.

However, it is still unknown how the mutations led to proinflammatory phenotype in FMF (27).

\section{Clinics}

\section{General characteristics of the FMF episodes}

FMF episodes are characterized by recurrent and short-lasting fever, peritonitis, synovitis, pleuritis and, rarely, inflammation and serositis that also include pericarditis. Clinical characteristics vary across the individuals or even across the members of the same family (36). The episodes are self-limiting generally within $12-72$ hours. The intervals between the episodes are irregular (from 1 week to several months or even years), the episodes are difficult to be foreseen. However, many patients may have prodromal signs (37). While some patients may show discomfort and irritability, others may show the signs such as myalgia, diarrhea, nausea and vomiting. Although prodromal signs are generally more common in the patients with abdominal episode, they may also be seen in those with pleural and 
articular episodes. While various clinical presentations may be seen in different episodes, the episodes may also have the same characteristics each time. The disease generally occurs within the first two decades of the life. It rarely begins after the age of forty. As the age becomes greater, the frequency and severity of the episodes generally decrease $(12,19,38)$.

There are many factors that trigger FMF episode. These include exposure to cold, lipid-rich nutrition, heavy exercise, surgical operations, infection, emotional stress, cisplatin and menstrual cycle $(12,39-40)$.

Furthermore, in the literature, there were 2 studies for this issue, which attracted our attention. The first publication reported that the episodes were more frequent and more severe in Helicobacter pylori (HP)-positive patients. In the other study, the same investigators observed that HP eradication led to lower levels of IL-6 before and after the episode (41-42). In the recent multicenter study performed by FMF study group that investigated the episodic characteristics of the patients with FMF in our country, clinical characteristics of the patients were reported to include peritonitis (93.7\%), fever $(92.5 \%)$, arthritis $(47.4 \%)$, pleuritis $(31.2 \%)$, myalgia (39.6\%) and erysipelas-like erythema (20.9\%) (18).

\section{(a) Fever}

Fever may be the only symptom during the childhood (36). It may vary from a mild fever to $38-40^{\circ} \mathrm{C}$. It nearly always accompanies to episodes. In the patients on treatment, the fever may be absent during the episode (38). The number of the patients groups that described fever-free episodes is very low (19).

\section{(b) Abdominal episode}

Abdominal episode is the most commonly encountered type of episode in FMF (95\%) and it may be the first sign in the half of the patients. It may remain localized or it may be diffused. There may be a mild distension as well as a severe peritonitis presentation. During the physical examination, distension, rebound sensitivity and decreased intestinal sounds are observed. In the direct radiography, air-fluid levels may be seen. The episode is completely resolved within 2-3 days. While constipation observed during the episode, in $10-20 \%$ of the patients have diarrhea after the episode. As a result of the episodes, intraperitoneal adhesions may develop. Posterior peritoneum is rarely affected from FMF episodes and it may be confounded with renal colic and acute pelvic inflammatory disease. As abdominal episodes may be confounded with acute abdomen presentation in FMF, apendectomy and laparotomy may be needed. Based on the data of Turkish FMF study group, the incidences of appendectomy and cholecistectomy are $19 \%$ and $1.6 \%$, respectively. In the presence of abdominal episodes, the differential diagnosis from other reasons for acute abdomen is important. While abdominal pain resulting from other reasons progressively worsens, the episodes of FMF are spontaneously resolved. In patients with FMF, gastro- intestinal amyloidosis, inflammatory bowel disease, side effects of colchicine and vasculitis-related abdominal pain may also be seen, in addition to FMF episodes (11-12, 18, 19). In a previous study, FMF was detected in at least $2 \%$ of the patients who were presented to emergency department with the complaint of acute abdomen (19).

\section{(c) Pleural episode}

In FMF patients, the reason of chest pain is generally pleuritis and pericarditis. Pleuritis is manifested by bilateral respiratory and pleural friction sounds in the involved site and dyspnea accompanied by fever (43). It has an acute onset and rapid resolution. In the involved site of the pleura, the pain increases with inspirium, respiratory sounds decrease and temporary pleuresia may develop. Pleural effusion with exuda characteristics is completely resolved within 48 hours after the disappearance of the episode. It may be seen along with other episodes as well as alone (19). Pleuritis may last for up to 7 days. Concomitant pericarditis may be observed (39). Recurrent pericarditis episodes are seen in $0.5 \%$ of the patients with FMF and it causes retrosternal pain and ST segment abnormality on ECG. Pericardial episodes rarely cause tamponade and constructive pericarditis $(38,43-44)$.

\section{(d) Articular episode}

Articular involvement is a common feature in FMF. Arthralgia is more common than arthritis. It may remain as the only symptom of the disease for years during the childhood. It is generally accompanied by high fever within the first 24 hours. Generally, large joints of the lower extremities are affected. Articular episodes may be triggered by mild trauma and exercise. The complaints peak within 24-48 hours and rapidly resolve. Arthritis episodes may occasionally last for up to 1-4 weeks. The joint involved is quite painful and limited. Despite the severe arthritis presentation, redness and swelling are less than expected. Synovial fluid is sterile, with a turbid and purulent appearance. It was reported that the risk for amyloidosis was 3-fold higher in the patients with articular episodes compared to those without. In addition, this group of patient is differentiated from FMF patients without arthritis with erysipelas-like erythema, myalgia, vasculitis and the onset at an earlier age $(12,18,19)$. It is more common in Jewish people of North African origin compared to those with other ethnicities. It mainly has 3 forms in FMF: First one is asymmetric, non-destructive arthritis $(75 \%)$ that leads to rapidly increasing effusion in 1 or 2 joints. Most commonly affected sites include knee and ankle. Generally, a complete resolution without sequels is seen. Second form is chronic destructive arthritis with an incidence rate of $2-5 \%$. In this form, most commonly affected joint is knee and sacroiliac joint is rarely affected $(0.4 \%)$. HLA B27 is typically negative. Lastly, FMF patients may have migratory polyarticular joint involvement. This group of patients may be misdiagnosed with acute rheumatoid disease (38). 


\section{(e) Other involvements and Amyloidosis}

Erysipelas-like erythema is seen in $7-40 \%$ of the patients with FMF. It occurs at dorsa pedis, ankle and on the surface of the leg extensor site. It is commonly accompanied by fever and occasionally by arthralgia. Erythema spontaneously resolves within 2-3 days. Splenomegalia (SM) is seen with an incidence of $30-50 \%$. However, SM cases often have negative result of rectal biopsy for amyloidosis. The incidences of hepatomegalia and lymphadenopathy are $20 \%$ and $6 \%$, respectively. Other rare symptoms include aseptic meningitis and acute orchitis. Scrotal edema that results from the inflammation of the tunica vaginalis spontaneously resolves within 12-24 hours. During the course of the disease, myalgia that may be related to arthritis in the upper and lower extremities may occur. Myalgia may rarely be the single symptom of the FMF. Furthermore, recurrent aptha, handfoot edema, purpura and erythema nodosum may develop $(19,38)$. Prolonged febrile myalgia is an uncommon serious symptom of FMF. Severe muscular pain and tenderness are present. It is characterized by high fever, hypergammaglobulinemia, increased erythrocyte sedimentation rate (ESR), normal muscle degredation enzymes and non-specific inflammatory myopathic changes on electromyography. It generally occurs in lower extremities and it is often bilateral. If left untreated, it may last for up to 6 weeks and it requires high-dose steroid therapy (45). Streptococci may promote this syndrome (46).

Amyloidosis is a serious complication of FMF. It does not depend on frequency, type and severity of the episodes. It preferentially affects the kidneys and it may lead to end-stage renal disease. Amyloidosis is manifested with proteinuria and it may involve gastrointestinal system, liver, adrenal gland, lungs, spleen and, later, heart and testis. Its frequency is correlated with ethnicity and, according to some studies, gene mutations. In some patients with amyloidosis, there is no typical FMF episode. However, the family members of these patients may have FMF symptoms. Amyloidosis is more commonly seen in North Africa-originated Jewish and Turkish populations compared to other communities (19, 38). Based on data of Turkish FMF study group, its incidence is $12.9 \%$ (18). In another study recently performed in our country, the incidence rate was decreased to about $2.9 \%$ (47). Decreased incidence of amyloidosis may be probably explained by early diagnosis, higher level of awareness of the patients and treatment.

In patients with FMF, fibrilar glomerulonephritis (GN), mesengial proliferative GN, HSP and PAN-related renal involvement may be seen, in addition to amyloidosis (12). In a recent data reported by Kukuy et al. among 25 FMF patients with more than $0.5 \mathrm{~g} / 24 \mathrm{~h}$ proteinuria, renal biopsy showed that 10 of them were non-amyloidal kidney disease, so they recommended to perform renal biopsy from patients with FMF and proteinuria more than $0.5 \mathrm{~g} / 24 \mathrm{~h}$ (48). There are case reports and some studies that suggest that vasculitis may develop during the course of FMF. Ozdogan H. et al. (49) reported the incidences of Henoch Schönlein Purpura
(HSP) and Polyarthritis Nodosa (PAN) with FMF as 7\% and $1 \%$, respectively. Based on the data of Turkish FMF study group (18), the incidences of HSP and PAN are $2.7 \%$ and $0.9 \%$, respectively. There was a case report in which the concomitance of HSP and PAN responding to intravenous immunoglobulin therapy was reported in a pediatric FMF patient (50).

Eventhough rarely, the concomitance of Behçet's disease, ARA, acute streptococcic GN, seronegative spondyloarhtropathies, inflammatory bowel disease and systemic lupus erythematosus (SLE) with FMF were reported $(18,51-53)$.

\section{FMF and Clinical-Subclinical Inflammation}

During the episodes, a non-specific acute phase response is observed. Mild leukocytosis and increase of C-reactive protein (CRP), ESR and other acute phase reactants are observed (54-55). In the majority of the patients, there are SM, decreased bone density, normochromic normocytic anemia and, in the children, growth retardation, which all reflect chronic immune activation. CRP and the precursor of the AA amyloid fibrils called SAA are sensitive and reliable inflammation markers. Despite the treatment with colchicine, both CRP and SAA increased in $30-90 \%$ of the patients during episode-free period (1, 56-59). Furthermore, during episode-free period, inflammatory markers such as lipoprotein(a), homocysteine and adrenomedullin also increase $(1,60)$. The level of S100-A12 released from active neutrophils is increased in the patients with or without active FMF despite the treatment with colchicine $(1,61)$. IL-6 and IL-8 are also increased during episode-free period. Although their levels are decreased under the treatment with colchicine, the transcription rates remain unchanged (54, 62-63). In addition, IL-10, IL-12, IL-17 and IL-18 were also reported to increase during episode-free period. Although IL-1 $\beta$ concentrations are important in the pathogenesis of FMF, it was seen that they were normal or even decreased during the episodic periods. This is tried to be explained by short half-life of IL-1 $\beta$ and the hypothesis that the level of IL-1 $\beta$ return to normal range without the occurrence of clinical symptoms after triggering the inflammation $(1,64)$. It was reported that, during episode-free period, tumor necrosis factor (TNF) (62), interferon- $\gamma$ (IFN) (65), vascular endothelial growth factor receptor-1 (VEGF-1) (66), and soluble intercellular adhesion molecule-1 (SICAM-1) (67) were increased. Briefly, subclinical inflammation persists not only in the attack episodes, but also in clinically silent periods.

\section{Diagnosis and Prognosis}

For the diagnosis of FMF, there is no diagnostic laboratory test and clinical findings are fundamental for the diagnosis. The diagnosis is based on familial history, patients' response to colchicine, typical features of the episodes and the exclusion of other reasons for periodic fever. Although the response to colchicine was high and the 
episodes were severe, it is typically spontaneously healed (11). It is diagnosed based on clinical symptoms, including Tel-Hashomer (68) criteria set (Table 1). New diagnostic criteria among children patients developed by Yalcinkaya and Ozen (69) are the most important diagnostic achievement for the last period (Table 2). However, it may not be appropriate to use these criteria in adult population. In the pediatric patients, the diagnosis is more comprehensive to avoid any delay. Genetic analysis is useful to confirm the diagnosis of FMF in the suspected patients who shows late-onset, atypical clinical symptoms without ethnic or familial history (20). However, mutation cannot be detected in some patients with FMF who responded to colchicine therapy (11). This may be explained by a probable unknown mutation as well as the presence of an atypical subgroup. Metaraminol provocation test and dopamine $\beta$ hydroxylase measurement are both dangerous and unpractical tests (7071). For the severity of FMF; some scoring systems were developed. One of them is Pras score (72). According to this scale, a score between 3 and 5 points; mild disease, a score between 6 and 8; moderate disease and a score $>9$; severe disease (Table 3). Another scoring system was defined by Mor et al. that consists of two sets of criteria, for patients not yet taking colchicine (F-SS-1) or receiving colchicine, and not recalling the frequency or the duration of the attacks before its use (F-SS-2) (Table 4-5). This scoring system has $\geq 92 \%$ sensitivity and specificity rate for distinguishing severe and non-severe disease (73).

For prognosis, the studies for genotype-phenotype correlation showed the relationship of M694V mutation with more severe disease (74-75). However, the evaluation of the Turkish FMF study group did not show this relation (18).

Tab. 1: Simplified criteria set for diagnosis of familial Mediterranean fever.

\begin{tabular}{|l|c|}
\hline Major criteria & Minor criteria \\
\hline 1.-4. Typical attacks & 1.-2. Incomplete attacks involving one or more of the following sites \\
\hline 1. Peritonitis (generalized) & 1. Chest \\
\hline 2. Pleuritis (unilateral) or pericarditis & 2. Join \\
\hline 3. Monarthritis (hip, knee, mklc) & 3. Exertional leg pain \\
\hline 4. Fever alone & 4. Favorable response to colchicine \\
\hline 5. Incomplete abdominal attack & \\
\hline
\end{tabular}

Absolute diagnosis: two major or one major and two minor criteria

Probable diagnosis: one major and one minor criterion

Table 2: Criteria set for the diagnosis of familial Mediterranean fever in childhood.

\begin{tabular}{|l|c|}
\hline Criteria & Description \\
\hline Fever & $\begin{array}{c}\text { Axillary temperature of }>38^{\circ} \mathrm{C} \\
6-72 \mathrm{~h} \text { of duration, } \geq 3 \text { attacks }\end{array}$ \\
\hline Abdominal pain & $6-72 \mathrm{~h}$ of duration, $\geq 3$ attacks \\
\hline Chest pain & $6-72 \mathrm{~h}$ of duration, $\geq 3$ attacks \\
\hline Arthritis & $6-72 \mathrm{~h}$ of duration, $\geq 3$ attacks, oligoarthritis \\
\hline Family history of FMF & \\
\hline
\end{tabular}

Table 3. Disease Severity Score.

\begin{tabular}{|l|r|c|}
\hline Parameter & & Degree of severity \\
\hline Age of onset (yr) & $>31$ & 0 \\
\hline & $31-31$ & 1 \\
\hline & $11-20$ & 2 \\
\hline & $6-10$ & 3 \\
\hline $\begin{array}{l}\text { Number of attacks } \\
\text { per month }\end{array}$ & $<6$ & 4 \\
\hline & $<1$ & 1 \\
\hline & $1-2$ & 2 \\
\hline
\end{tabular}

\begin{tabular}{|l|c|c|}
\hline Parameter & & Degree of severity \\
\hline Presence of atrthritis & Acute & 2 \\
\hline & Protracted & 3 \\
\hline $\begin{array}{l}\text { Presence of erysipelas-like } \\
\text { erythema }\end{array}$ & & 2 \\
\hline Presence of amyloidosis & & 3 \\
\hline Colchicine dose (mg/day) & 1 & 1 \\
\hline & 1.5 & 2 \\
\hline & 2 & 3 \\
\hline & $>2$ & 4 \\
\hline
\end{tabular}


Tab. 4: F-SS-1 - Determination of Degree of Severity in FMF Patients*.

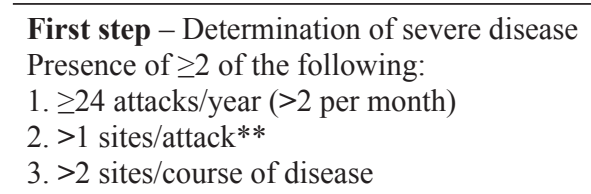

Second step - Determination of disease with intermediate severity (In a disease not defined as severe by the above criteria) Presence of $\geq 1$ of the following:

1. $\geq 18$ attacks/year

2. Duration of attack $\geq 4$ days***

Third step - Determination of mild disease

Absence of criteria defining severe or intermediate forms of FMF.

*FMF: Familial Mediterranean fever; F-SS-1: First set of criteria for FMF severity score.

$* *$ In at least $25 \%$ of the attacks.

***In most attacks.

Tab. 5: F-SS-2 - Determination of the Degree of Severity in FMF Patients*.

\section{Criteria}

1. $>1$ site in a single attack.**

2. $>2$ sites in the course of the disease.

3. $\geq 2 \mathrm{mg}$ /day colchicine to achieve remission.

4. $\geq 2$ pleuritic attacks during the course of the disease.

5. $\geq 2$ Erysipelas-like erythema attacks during the course of the disease.

6. Age of onset $\leq 10$ years.

Severe disease $\geq 3$ criteria; intermediate disease $=2$ criteria; mild disease $\leq 1$ criterion.

*FMF: Familial Mediterranean fever; F-SS-2: Second set of criteria for FMF severity score.

$* *$ In at least $25 \%$ of the attacks.

\section{Differential Diagnosis}

As FMF has a course only with arthritis, especially during the childhood, it may be confounded with acute articular rheumatism, juvenile idiopathic arthritis, systemic lupus erythematosus and viral infections. As stated before, due to the potential presence of vasculitis as a presentation symptom in the patients with FMF (PAN, HSP), it may also be confounded with diseases of this group. Abdominal episodes that are very similar to acute abdomen presentation may be seen in the patients with FMF. Therefore, it may be confounded with any reason that cause acute abdomen. Because of the involvement of posterior peritoneum, it should be differentiated from renal colic and acute pelvic inflammatory disease. In addition, it may be confounded with other familial periodic fever syndromes, including Tumor Necrosis Factor receptor-related periodic syndrome (TRAPS), Hyperimmunoglobulin D syndrome (HIDS), Muckle-Wells Syndrome
(MWS), Familial Cold Urticaria (FCU), chronic infantile neurologic cutaneous and articular syndrome, PFAPA (periodic fever, aphtous stomatitis, pharyngitis and adenopatia) syndrome. TRAPS is an autosomal dominant disease. It generally begins during the childhood or adolescence. It is characterized by recurrent febrile episodes, rash, periorbital edema, musculoskeletal pain and abdominal pain. Duration of episode is variable, as does in FMF, but it lasts for a longer period. It is different from FMF for responding to steroid therapy (76-77). In HIDS, there is mevolonate kinase deficiency. Blood IgD level is constantly elevated. Peritonitis is not observed and self-limiting recurrent fever, synovial and serosal inflammation, rash, uveitis or conjunctivitis and, in some cases, amyloidosis are seen $(11,78)$. In MWS and FCU, urticarial rash is marked. In PFAPA syndrome, periodic fever, aphtous stomatitis, pharyngitis and adenopathy are seen. However, abdominal pain is not commonly seen. Despite the absence of response to colchicine, it responds well to steroid therapy (79-80).

\section{Treatment}

Colchicine has been used to prevent FMF episodes and to reduce the frequency and severity of the episodes since 1970s. The efficacy of the colchicine has been demonstrated by Zemer et al. in $1974(8,81)$. In the study performed by Ozcakar et al. (82), they investigated the effects of the colchicine on subclinical inflammation and they observed that quality of life and laboratory findings improved after the administration of colchicine. It inhibits microtubular system during the metaphase. It decreases monocyte and neutrophil chemotaxis. The dose of colchicine is $1-1.5 \mathrm{mg} /$ day, regardless of weight, age and disease severity. During the follow-up, the dose is established according to clinical characteristics of the patient $(8,19)$. Articular findings are refractory to the treatment with colchicine. Steroid therapy is not used, except for vasculitis (19). When received at a sufficient dose, colchicine prevents amyloidosis, which is the most important complication of FMF. Its preventive effect occurs when it is regularly used. It also provides improvement in patients who developed renal amyloidosis (83-84). Side effects of colchicine include gastrointestinal intolerance (diarrhea, nausea and abdominal pain), bone marrow suppression, myopathia, alopecia, peripheral neuropathy, oligospermia and myopathia (11). In patients who developed amyloidosis-related ESRD, the therapy with colchicine should be continued after the transplantation. In patients who underwent transplantation due to amyloidosis, long-term results are similar to those observed in general transplantation population (85-86). As colchicine will be given concomitantly to immunosuppressive therapies, drug interactions and dose adjustment should be considered for side effects.

Thalidomide is a selective inhibitor of TNF- $\alpha$ (87). It decreases the phagocytosis of the monocyte. In patients with therapy-resistant FMF, it was shown to decrease the episode 
frequency. However, its use is limited due to its toxic effects such as teratogenicity and peripheral neuropathy $(11,88)$.

There are some reports that TNF $\alpha$ relieves FMF episodes and prevents amyloidosis. Especially, FMF patients with chronic hip involvement exhibited an improvement. However, given the role of TNF $\alpha$ in the pathogenesis, it is evident that more clinical studies are warranted (11).

In colchicine-resistant patients, IFN $\alpha$ was reported to shorten the episode duration in addition to control the episodes (89). Nevertheless, in a double-blind controlled study performed by the same investigators, no beneficial effect of IFN $\alpha$ could be demonstrated (90). However, in the study performed by Calguneri et al. (91), it was shown that, in colchicine-resistant patients, continuous IFN $\alpha$ therapy in addition to colchicine could be effective.

The place and importance of IL-1 in the pathogenesis of FMF is recognized. Anakinra, which is an IL-1 antagonist, was used for treatment and found to be efficient (92).

Selective serotonin re-uptake inhibitors (SSRIs) may decrease the episode frequency in the patients with episodes that continue despite the regular use of colchicine. This may be explained by the facts that stress and emotional status are among the triggering factors of FMF episodes and that proinflammatory cytokines play a role in the pathogenesis of the depression (93).

\section{References}

1. Ben-Zvi I, Livneh A. Chronic inflammation in FMF: markers, risk factors, outcomes and therapy. Nat Rev Rheumatol 2011; 7(2): 105-12.

2. Janeway TC, Mosenthal $\mathrm{H}$. Unusual paroxysmal syndrome, probably allied to recurrent vomiting, with a study of nitrogen metabolism. Trans Assoc Am Physicians 1908; 23: 504518

3. Siegal S. Benign paroxysmal peritonitis. Ann Intern Med 1945; 13: 1-22.

4. Marmarali A. Garip bir karin sendromu. Turk Tip Cemy Mecm 1946; 12: 436-443.

5. Mamou H, Cattan R. La maladie periodique. Sem Hop Paris 1952; 1062-70.

6. Heller H, Sohar E, Sherf L. Familial Mediterranean fever. AMA Arch Intern Med 1958; 102(1): 50-71.

7. Ozkan E. A new approach to the treatment of periodic fever. Med Bull Istanbul 1972; 5: 44-9.

8. Goldfinger SE. Colchicine for familial Mediterranean fever. N Engl J Med 1972; 287(25): 1302

9. The International FMF Consortium. Ancient missense mutations in a new member of the RoRet gene family are likely to cause familial Mediterranean fever. Cell 1997; 90(4): 797-807.

10. French FMF Consortium. A candidate gene for familial Mediterranean fever. Nat Genet 1997; 17(1): 25-31.

11. Onen F. Familial Mediterranean fever. Rheumatol Int 2006; 26(6): 489-96.

12. Fonnesu C, Cerquaglia C, Giovinale M, et al. Familial Mediterranean Fever: a review for clinical management. Joint Bone Spine 2009; 76(3): 227-33.

13. Onen F, Sumer H, Turkay S, Akyurek O, Tunca M, Ozdogan H. Increased frequency of familial Mediterranean fever in Central Anatolia, Turkey. Clin Exp Rheumatol 2004; 22(4 Suppl 34): S31-3.

14. Cobankara V, Fidan G, Turk T, Zencir M, Colakoglu M, Ozen S. The prevalence of familial Mediterranean fever in the Turkish province of Denizli: a field study with a zero patient design. Clin Exp Rheumatol 2004; 22(4 Suppl 34): S27-30.

15. Kisacik B, Yildirim B, Tasliyurt T, et al. Increased frequency of familial Mediterranean fever in northern Turkey: a population-based study. Rheumatol Int 2009; 29(11): 1307-9

16. Cakir N, Pamuk ON, Dervis E, et al. The prevalences of some rheumatic diseases in western Turkey: Havsa study. Rheumatol Int 2012; 32(4): 895-908.

17. Ozdogan H. Sivas' in Zara ilçesinde AAA Prevalansı. In: Familial Mediterranean Fever Working Group 2010 Oct 13-17, XI National Congress of Rheumatology, Antalya 2010 , p. $234-6$

18. Tunca M, Akar S, Onen F, et al. Familial Mediterranean fever (FMF) in Turkey: results of a nation wide multicenter study. Medicine (Baltimore) 2005; 84(1): 1-11.
19. Cobankara V, Balkarli A. Ailesel Akdeniz Ateşi. Pam Med J 2011; 4(2): 86-98.

20. Dundar M, Emirogullari EF, Kiraz A, Taheri S, Baskol M. Common Familial Mediterranean Fever gene mutations in a Turkish cohort. Mol Biol Rep 2011; 38(8): 5065-9.

21. Yilmaz E, Ozen S, Balci B, et al. Mutation frequency of Familial Mediterranean Fever and evidence for a high carrier rate in the Turkish population. Eur J Hum Genet 2001; 9(7): 553-5.

22. Aladag A, Comlekoglu ME, Dundar M, Gungor MA, Artunc C. Effects of soldering and laser welding on bond strength of ceramic to metal. J Prosthet Dent 2011; 105(1): 28-34.

23. Steiner AA, Chakravarty S, Rudaya AY, Herkenham M, Romanovsky AA. Bacterial lipopolysaccharide fever is initiated via Toll-like receptor 4 on hematopoietic cells. Blood 2006; 107(10): 4000-2.

24. Dinarello CA. Infection, fever, and exogenous and endogenous pyrogens: some concepts have changed. J Endotoxin Res 2004; 10(4): 201-22.

25. Creagh EM, O'Neill LA. TLRs, NLRs and RLRs: a trinity of pathogen sensors that co-operate in innate immunity. Trends Immunol 2006; 27(8): 352-7.

26. Dinarello CA. Unraveling the NALP-3/IL-1beta inflammasome: a big lesson from a small mutation. Immunity 2004 Mar; 20(3): 243-4.

27. Simon A, van der Meer JW. Pathogenesis of familial periodic fever syndromes or hereditary autoinflammatory syndromes. Am J Physiol Regul Integr Comp Physiol 2007; 292(1): 86-98.

28. Samuels J, Aksentijevich I, Torosyan Y, et al. Familial Mediterranean fever at the millennium. Clinical spectrum, ancient mutations, and a survey of 100 American referrals to the National Institutes of Health. Medicine (Baltimore) 1998; 77(4): $268-97$.

29. Guz G, Kanbay M, Ozturk MA. Current perspectives on familial Mediterranean fever. Curr Opin Infect Dis 2009; 22(3): 309-15.

30. Bertin J, DiStefano PS. The PYRIN domain: a novel motif found in apoptosis and inflammation proteins. Cell Death Differ 2000; 7(12): 1273-4.

31. Brydges S, Kastner DL. The systemic autoinflammatory diseases: inborn errors of the innate immune system. Curr Top Microbiol Immunol 2006; 305: 127-60.

32. Richards N, Schaner P, Diaz A, et al. Interaction between pyrin and the apoptotic speck protein (ASC) modulates ASC-induced apoptosis. J Biol Chem 2001; 276(42): 39320-9.

33. Chae JJ, Komarow HD, Cheng J, et al. Targeted disruption of pyrin, the FMF protein, causes heightened sensitivity to endotoxin and a defect in macrophage apoptosis. Mol Cell 2003; 11(3): 591-604.

34. Chae JJ, Wood G, Masters SL, et al. The B30.2 domain of pyrin, the familial Mediterranean fever protein, interacts directly with caspase-1 to modulate IL-1beta production. Proc Natl Acad Sci USA 2006; 103(26): 9982-7.

35. Yu JW, Wu J, Zhang Z, et al. Cryopyrin and pyrin activate caspase-1, but no NF-kappaB, via ASC oligomerization. Cell Death Differ 2006; 13(2): 236-49.

36. Shohat M, Halpern GJ. Familial Mediterranean fever - a review. Genet Med 2011; 13(6): 487-98.

37. Lidar M, Yaqubov M, Zaks N, Ben-Horin S, Langevitz P, Livneh A. The prodrome: a prominent yet overlooked pre-attack manifestation of familial Mediterranean fever. J Rheumatol 2006; 33(6): 1089-92.

38. Ben-Chetrit E, Levy M. Familial Mediterranean fever. Lancet 1998; 351(9103): 659-64.

39. Ben-Chetrit E, Ben-Chetrit A. Familial Mediterranean fever and menstruation. BJOG 2001; 108(4): 403-7.

40. Toubi E, Gershoni-Baruch R, Kuten A. Cisplatin treatment triggers familial Mediterranean fever attacks. Tumori 2003; 89(1): 80-1.

41. Demirturk L, Ozel AM, Cekem K, Yazgan Y, Gultepe M. Co-existence of Helicobacter pylori infection in patients with Familial Mediterranean Fever (FMF) and the effect of Helicobacter pylori on the frequency and severity of FMF attacks. Dig Liver Dis 2005; 37(3): 153-8

42. Ozel AM, Demirturk L, Aydogdu A, et al. Effect of Helicobacter pylori infection and eradication therapy on interleukin-6 levels in patients with Familial Mediterranean Fever Int J Clin Pract 2008; 62(5): 754-61.

43. Zadeh N, Getzug T, Grody WW. Diagnosis and management of familial Mediterranean fever: integrating medical genetics in a dedicated interdisciplinary clinic. Genet Med 2011; 13(3): 263-9.

44. Kees S, Langevitz P, Zemer D, Padeh S, Pras M, Livneh A. Attacks of pericarditis as a manifestation of familial Mediterranean fever (FMF). QJM 1997; 90(10): $643-7$.

45. Langevitz P, Zemer D, Livneh A, Shemer J, Pras M. Protracted febrile myalgia in patients with familial Mediterranean fever. J Rheumatol 1994; 21(9): 1708-9.

46. Soylu A, Kasap B, Turkmen M, Saylam GS, Kavukcu S. Febrile myalgia syndrome in familial Mediterranean fever. J Clin Rheumatol 2006; 12(2): 93-6.

47. Akse-Onal V, Sag E, Ozen S, et al. Decrease in the rate of secondary amyloidosis in Turkish children with FMF: are we doing better? Eur J Pediatr 2010; 169(8): $971-4$.

48. Kukuy O, Livneh A, Ben-David A, et al. Familial Mediterranean fever (FMF) with proteinuria: clinical features, histology, predictors, and prognosis in a cohort of 25 patients. J Rheumatol 2013; 40(12): 2083-7.

49. Ozdogan H, Arisoy N, Kasapcapur O, et al. Vasculitis in familial Mediterranean fever. J Rheumatol 1997; 24(2): 323-7. 
50. Girisgen I, Sonmez F, Koseoglu K, Erisen S, Yilmaz D. Polyarteritis nodosa and Henoch-Schonlein purpura nephritis in a child with familial Mediterranean fever: a case report. Rheumatol Int 2012; 32(2): 529-33.

51. Tekin M, Yalcinkaya F, Tumer N, Cakar N, Kocak H. Familial Mediterranean fever and acute rheumatic fever: a pathogenetic relationship? Clin Rheumato $1999 ; 18(6): 446-9$.

52. Cattan D, Notarnicola C, Molinari N, Touitou I. Inflammatory bowel disease in non-Ashkenazi Jews with familial Mediterranean fever. Lancet 2000; 355(9201): $378-9$

53. Langevitz P, Livneh A, Zemer D, Shemer J, Pras M. Seronegative spondyloarthropathy in familial Mediterranean fever. Semin Arthritis Rheum 1997; 27(2): 67-72.

54. Livneh A, Langevitz P, Zemer D, et al. The changing face of familial Mediterranean fever. Semin Arthritis Rheum 1996; 26(3): 612-27.

55. Gang N, Drenth JP, Langevitz P, et al. Activation of the cytokine network in familial Mediterranean fever. J Rheumatol 1999; 26(4): 890-7.

56. Lachmann HJ, Sengul B, Yavuzsen TU, et al. Clinical and subclinical inflammation in patients with familial Mediterranean fever and in heterozygous carriers of MEFV mutations. Rheumatology (Oxford) 2006; 45(6): 746-50.

57. Korkmaz C, Ozdogan H, Kasapcopur O, Yazici H. Acute phase response in familial Mediterranean fever. Ann Rheum Dis 2002; 61(1): 79-81.

58. Duzova A, Bakkaloglu A, Besbas N, et al. Role of A-SAA in monitoring subclinical inflammation and in colchicine dosage in familial Mediterranean fever. Clin Exp Rheumatol 2003; 21(4): 509-14

59. Tunca M, Kirkali G, Soyturk M, Akar S, Pepys MB, Hawkins PN. Acute phase response and evolution of familial Mediterranean fever. Lancet 1999; 353(9162): 1415 .

60. Balat A, Islek I, Cekmen M, et al. Adrenomedullin and total nitrite levels in children with familial Mediterranean fever. J Paediatr Child Health 2006; 42(5): 240-3.

61. Kallinich T, Wittkowski H, Keitzer R, Roth J, Foell D. Neutrophil-derived S100A12 as novel biomarker of inflammation in familial Mediterranean fever Ann Rheum Dis 2010; 69(4): 677-82.

62. Kiraz S, Ertenli I, Arici M, et al. Effects of colchicine on inflammatory cytokine and selectins in familial Mediterranean fever. Clin Exp Rheumatol 1998; 16(6): $721-4$.

63. Notarnicola C, Didelot MN, Seguret F, Demaille J, Touitou I. Enhanced cytokine mRNA levels in attack-free patients with familial Mediterranean fever. Genes Immun 2002; 3(1): 43-5.

64. Dinarello CA. Blocking IL-1 in systemic inflammation. J Exp Med 2005; 201(9): 1355-9.

65. Koklu S, Ozturk MA, Balci M, Yuksel O, Ertenli I, Kiraz S. Interferon-gamma levels in familial Mediterranean fever. Joint Bone Spine 2005; 72(1): 38-40.

66. Basar O, Ozturk MA, Koklu S, et al. Plasma levels of soluble vascular endothelia growth factor receptor-1 (sVEGFR-1) in familial Mediterranean fever. Joint Bone Spine 2007; 74(1): 52-5.

67. Direskeneli H, Ozdogan H, Korkmaz C, Akoglu T, Yazici H. Serum soluble intercellular adhesion molecule 1 and interleukin 8 levels in familial Mediterranean fever. J Rheumatol 1999; 26(9): 1983-6.

68. Livneh A, Langevitz P, Zemer D, et al. Criteria for the diagnosis of familial Mediterranean fever. Arthritis Rheum 1997; 40(10): 1879-85.

69. Yalcinkaya F, Ozen S, Ozcakar ZB, et al. A new set of criteria for the diagnosi of familial Mediterranean fever in childhood. Rheumatology 2009; 48(4): 395-8.

70. Ben-Chetrit E, Gutman A, Levy M. Dopamine-beta-hydroxylase activity in familial Mediterranean fever. Lancet 1990; 335(8682): 176

71. Courillon-Mallet A, Cauet N, Dervichian M, Launay JM, Cattan D. Plasma dopamine beta-hydroxylase activity in familial Mediterranean fever. Isr J Med Sc 1992; 28(7): 427-9.

72. Pras E, Livneh A, Balow JE, Jr., Kastner DL, Pras M, Langevitz P. Clinical differences between North African and Iraqi Jews with familial Mediterranean fever. Am J Med Genet 1998; 75(2): 216-9.
73. Mor A, Shinar Y, Zaks N, et al. Evaluation of disease severity in familial Mediterranean fever. Semin Arthritis Rheum. 2005; 35(1): 57-64

74. Gershoni-Baruch R, Brik R, Shinawi M, Livneh A. The differential contribution of MEFV mutant alleles to the clinical profile of familial Mediterranean fever. Eur J Hum Genet 2002; 10(2): 145-9.

75. Sakallioglu O, Gok F, Kalman S, Gul D, Gokcay E. The phenotype-genotype correlations of FMF patients: a single center study. Rheumatol Int 2006; 26(7): 638-40.

76. Gattorno M, Pelagatti MA, Meini A, et al. Persistent efficacy of anakinra in patients with tumor necrosis factor receptor-associated periodic syndrome. Arthritis Rheum 2008; 58(5): 1516-20.

77. Dode C, Andre M, Bienvenu T, et al. The enlarging clinical, genetic, and population spectrum of tumor necrosis factor receptor-associated periodic syndrome. Arthritis Rheum 2002; 46(8): 2181-8

78. Sinha A, Waterham HR, Sreedhar KV, Jain V. Novel mutations causing hyperimmunoglobulin D and periodic fever syndrome. Indian Pediatr 2012; 49(7): 583-5.

79. Federici S, Caorsi R, Gattorno M. The autoinflammatory diseases. Swiss Med Wkly 2012; 142: 13602

80. Padeh S, Brezniak N, Zemer D, et al. Periodic fever, aphthous stomatitis, pharyngitis, and adenopathy syndrome: clinical characteristics and outcome. J Pediat 1999; 135(1): 98-101.

81. Zemer D, Revach M, Pras M, et al. A controlled trial of colchicine in preventing attacks of familial mediterranean fever. N Engl J Med 1974; 291(18): 932-4.

82. Ozcakar ZB, Yalcinkaya F, Yuksel S, Acar B, Gokmen D, Ekim M. Possible effect of subclinical inflammation on daily life in familial Mediterranean fever. Clin Rheumatol 2006; 25(2): 149-52.

83. Livneh A, Zemer D, Langevitz P, Laor A, Sohar E, Pras M. Colchicine treatmen of AA amyloidosis of familial Mediterranean fever. An analysis of factors affecting outcome. Arthritis Rheum 1994; 37(12): 1804-11.

84. Zemer D, Pras M, Sohar E, Modan M, Cabili S, Gafni J. Colchicine in the prevention and treatment of the amyloidosis of familial Mediterranean fever. N Engl J Med 1986; 314(16): 1001-5.

85. Livneh A, Zemer D, Siegal B, Laor A, Sohar E, Pras M. Colchicine prevents kidney transplant amyloidosis in familial Mediterranean fever. Nephron 1992; 60(4): 418-22.

86. Keven K, Sengul S, Kutlay S, et al. Long-term outcome of renal transplantation in patients with familial Mediterranean fever amyloidosis: a single-center experience. Transplant Proc 2004; 36(9): 2632-4.

87. Sampaio EP, Sarno EN, Galilly R, Cohn ZA, Kaplan G. Thalidomide selectively inhibits tumor necrosis factor alpha production by stimulated human monocytes. J Exp Med 1991; 173(3): 699-703.

88. Seyahi E, Ozdogan H, Masatlioglu S, Yazici H. Successful treatment of familial Mediterranean fever attacks with thalidomide in a colchicine resistant patient. Clin Exp Rheumatol 2002; 20(26): 43-4.

89. Tunca M, Tankurt E, Akbaylar Akpinar H, Akar S, Hizli N, Gonen O. The efficacy of interferon alpha on colchicine-resistant familial Mediterranean fever attacks: a pilot study. Br J Rheumatol 1997; 36(9): 1005-8.

90. Tunca M, Akar S, Soyturk M, et al. The effect of interferon alpha administration on acute attacks of familial Mediterranean fever: A double-blind, placebo-controlled trial. Clin Exp Rheumatol 2004; 22(34): 37-40.

91. Calguneri M, Apras S, Ozbalkan Z, Ozturk MA, Ertenli I, Kiraz S. The efficacy of continuous interferon alpha administration as an adjunctive agent to colchicine-resistant familial Mediterranean fever patients. Clin Exp Rheumatol 2004; 22(34): 41-4.

92. Roldan R, Ruiz AM, Miranda MD, Collantes E. Anakinra: new therapeutic approach in children with Familial Mediterranean Fever resistant to colchicine. Joint Bone Spine 2008; 75(4): 504-5.

93. Onat AM, Ozturk MA, Ozcakar L, et al. Selective serotonin reuptake inhibitors reduce the attack frequency in familial mediterranean Fever. Tohoku J Exp Med 2007; 211(1): 9-14.

\title{
Corresponding author:
}

\author{
Adem Kucuk, Necmettin Erbakan Üniversitesi Romatoloji Bilim Dalı Konya,Turkey; e-mail: drademk@yahoo.com
}

